IZA DP No. 5547

Are We Wasting Our Children's Time by

Giving Them More Homework?

Ozkan Eren

Daniel J. Henderson

March 2011 


\title{
Are We Wasting Our Children's Time by Giving Them More Homework?
}

\author{
Ozkan Eren \\ University of Nevada, Las Vegas \\ Daniel J. Henderson \\ State University of New York at Binghamton \\ and IZA \\ Discussion Paper No. 5547 \\ March 2011 \\ IZA \\ P.O. Box 7240 \\ 53072 Bonn \\ Germany \\ Phone: +49-228-3894-0 \\ Fax: +49-228-3894-180 \\ E-mail: iza@iza.org
}

Any opinions expressed here are those of the author(s) and not those of IZA. Research published in this series may include views on policy, but the institute itself takes no institutional policy positions.

The Institute for the Study of Labor (IZA) in Bonn is a local and virtual international research center and a place of communication between science, politics and business. IZA is an independent nonprofit organization supported by Deutsche Post Foundation. The center is associated with the University of Bonn and offers a stimulating research environment through its international network, workshops and conferences, data service, project support, research visits and doctoral program. IZA engages in (i) original and internationally competitive research in all fields of labor economics, (ii) development of policy concepts, and (iii) dissemination of research results and concepts to the interested public.

IZA Discussion Papers often represent preliminary work and are circulated to encourage discussion. Citation of such a paper should account for its provisional character. A revised version may be available directly from the author. 
IZA Discussion Paper No. 5547

March 2011

\section{ABSTRACT}

\section{Are We Wasting Our Children's Time by Giving Them More Homework?}

Following an identification strategy that allows us to largely eliminate unobserved student and teacher traits, we examine the effect of homework on math, science, English and history test scores for eighth grade students in the United States. Noting that failure to control for these effects yields selection biases on the estimated effect of homework, we find that math homework has a large and statistically meaningful effect on math test scores throughout our sample. However, additional homework in science, English and history are shown to have little to no impact on their respective test scores.

JEL Classification: $\quad$ C23, I21, I28

Keywords: first differencing, homework, instrumental variable, selection bias, unobserved traits

Corresponding author:

Daniel J. Henderson

Department of Economics

State University of New York

Binghamton, NY 13902-6000

USA

E-mail: djhender@binghamton.edu 


\section{Introduction}

Homework has been an intensely debated topic in American history (Gill and Schlossman 1996). Contrary to the popular view today, homework has not always been viewed as a vital element in academics. During the late nineteenth and early twentieth centuries America had a strong "antihomework" movement. For example, Rice's (1897) study concluded that laborious devotion by children to their spelling homework bore no relation to later spelling ability. He decried what he termed "mechanical schooling" and argued that time spent on homework could be better spent on other activities. Others went as far as to say that homework was harmful to the mental and physical health of children (Bok 1900). Perhaps the height of this movement was in 1901 when the California state legislature passed a law abolishing homework for children under the age of fifteen and limited it in public high schools (California Civil Code 1901).

This sentiment of less homework was extinguished with the 1957 Soviet launching of Sputnik. The Cold War put pressure on students to keep up with their Russian counterparts. Homework was increased at all levels of education and a similar global competition drive in the 1980's with Japan led to increased standards accompanied by even more homework. The 1990's saw leading educational spokespersons push homework as essential to raise education standards and foster academic achievement. These increases in homework were partly designed to upgrade the quality of the labor force (What Works 1986). School districts across the country have since adopted mandatory policies on the number of hours of homework at different age groups (Cooper 1994).

This strong difference in opinion between the early and late twentieth century begs the question of why academic scholars have mostly ignored the issue of homework in academic achievement. Given the relatively low cost of homework as compared to other policy variables (say reduced class size), this lack of attention in the field of economics is even more concerning. Over the last four decades in the United States (among public schools) pupil-teacher ratios have fallen by around forty percent, and at the same time, teachers' median experience and the number of teachers holding graduate degrees have almost doubled. These vigorous changes have more than tripled the real expenditures per student (Hanushek 
2003). Unfortunately, the substantial growth in resources devoted to schools has not been accompanied by any significant changes in student achievement (Hoxby 1999; Hanushek 1979 and 2003). In light of these pessimistic findings, others investigate non-financial inputs (peer effects, school based incentive policies and institutional factors) of the educational production function (Angrist and Lang 2004; Figlio and Lucas 2003; Fuchs and Wößmann 2006, Walsh 2010; ). However, among these non-financial inputs, homework has been relatively unexplored.

We know of three (empirical) economic studies that examine the effects of homework on student outcomes. Aksoy and Link (2000), using the National Educational Longitudinal Study of 1988 (NELS:88) and relying on student responses regarding the hours of homework, find positive and significant effects of homework on tenth grade math test scores. Betts (1997), on the other hand, focuses on the hours of homework assigned by the teacher. This measure of homework is actually a policy variable, which the school or the teacher can control. Using the Longitudinal Study of American Youth, Betts obtains a substantial effect of homework on math test scores. Specifically, an extra half hour of math homework per night in grades 7 to 11 is estimated to advance a student nearly two grade equivalents. Furthermore, the author argues that virtually all students could benefit from extra homework and thus math teachers could increase almost all students' achievement by assigning more homework. Finally, Eren and Henderson (2008), using the measure of hours of homework assigned by the teacher with the NELS:88 data and nonparametric estimation techniques, find evidence of positive and significant effects of homework on tenth grade math test scores for nearly half of their sample. ${ }^{1}$

Our current study makes three distinct contributions to this small strand of the educational production function literature. First, unlike the aforementioned studies, we focus on a nationally representative sample of middle school (eighth grade) students. Given the existing evidence that the achievement divergence between gender and racial groups is more pronounced in childhood or early adolescence, understanding the role of homework at the middle school level may be more policy relevant. Second,

\footnotetext{
${ }^{1}$ In a complementary study, Stinebrickner and Stinebrickner (2008) examine the impact of a student's study effort on grade performance using liberal art school data and obtain a large and positive effect of studying.
} 
although math achievement is an important predictor of educational and labor market outcomes and its examination is necessary, the role of homework in math tells us little about the role of homework, in say, history. To this end, we extend the analysis to cover other academic subjects as well. Third and perhaps most importantly, following the identification strategy developed in Dee $(2005,2007)$, we exploit the matched pair feature of the data. Specifically, for every participating student in the base year, the NELS gathered information for two academic subject teachers, which allows us to observe two outcomes for each student. In addition, the surveyed teachers in the NELS usually teach multiple classes. This nature of the data makes it possible to construct contemporaneous within-student, within-teacher comparisons that largely eliminate unobserved student and teacher traits.

Our results show that controlling for unobserved characteristics play a crucial role in our estimations. In the absence of student (teacher) fixed effects, we observe positive (negative) selection biases on the effect of homework. With respect to given subjects, it is found that math homework consistently gives a statistically meaningful and large positive effect on test scores for the full sample. However, additional homework in science, English and history are shown to have little to no impact on test scores. Several robustness checks, including instrumental variable estimation, further support the findings. When we extend the analysis to subpopulations, we observe differential effects of additional homework. Specifically, the impact of math homework for black students relative to white students is much lower and statistically insignificant and there is evidence for beneficial effects of science homework for Hispanic students. Moreover, the results indicate significant and large effects of additional math homework for those whose parents have a high school diploma or some college. Finally, we do not observe any spillover effects of homework across related subjects.

\section{Data}

The data is obtained from the NELS:88, a large longitudinal study of eighth grade students conducted by the National Center for Educational Statistics. The NELS:88 is a stratified sample, which was chosen 
in two stages. In the first stage, a total of 1032 schools on the basis of school size were selected from a universe of approximately 40,000 schools. In the second stage, up to 26 students were selected from each of the sample schools based on race and gender. The original sample, therefore, contains approximately 25,000 surveyed eighth grade students.

To measure academic achievement, students were administered cognitive tests in math, science, English and history. In addition, for every participating student, the NELS:88 fielded questionnaires for two academic-subject teachers, whom provided information pertaining to their background and the classroom environment. The two surveyed teachers were selected by randomly assigning each sampled school to one of four subject area groupings: math/English, math/history, science/English and science/history. This nature of the data allows us to observe two outcomes for each student. That is, an outcome is observed for each student in each of the two sampled subjects along with data on the teacher of the student in the given subject.

We utilize eighth grade test scores as our dependent variable. Our variable of interest is the hours of homework assigned weekly and comes directly from the student's subject-specific teachers' reports. This measure of homework is a policy variable, which the school administrator or the teacher can control. Alternatively, one can rely on students responses as the measure of homework. However, for several reasons (for example, the age of students at the time survey) this variable is likely to suffer from a larger measurement error.

Even though our preferred specifications, described below, utilize contemporaneous within-student, within-teacher comparisons across two academic subjects along with variables that vary at the level of classroom and teacher, we also provide alternative specifications that rely on observable student and teacher traits. Doing so permits a better understanding of the direction/magnitude of potential biases inherent in the educational production function. Specifically, depending on the nature of the specifications, we are able to control for the following variables:

Student: gender, race, socioeconomic status of the family, region, urban/rural status; 
Teacher: gender, race, indicators for a graduate degree and state certification, experience, an indicator of whether the teacher and the student share the same gender, an indicator of whether the student and the teacher share the same race;

Classroom: class size, number of limited English proficiency students in class, number of hours the class meets weekly, weekly number of hours spent administering tests/quizzes;

Peer: teacher's evaluation of the overall class achievement level (high, average, low and widely differing), weekly number of hours spent maintaining order/discipline in class, percentage of textbook covered in course.

Observations with missing values for any of the variables defined above are dropped. The sample is further restricted to students who attend public schools, which yields a total of 25,794 student by teacher pairs (12,897 students). Table 1 reports the summary statistics of some of the key variables for the 33,802 student by teacher pairs (16,901 students) in the public school sample and for the regression sample used for estimation. The means and standard deviations in the regression sample are similar to those obtained when using the full set of potential public school observations. This similarity provides some assurance that missing values have not distorted our sample.

Since little is known about how weekly homework assignment vary across and within-teachers, we present some subject-specific descriptive statistics in Table 2 prior to the discussion of the empirical methodology. The average weekly hours of homework is similar across subjects (column 1); math teachers assign the most (2.4 hours), while science teachers assign the least (1.8 hours) amount of homework. The second and third columns of Table 2 report the overall and within-teacher standard deviation of assigned homework, respectively, and the final column gives the fraction of variance in weekly hours of homework that is across teachers. About $87 \%$ of the variance in weekly assigned math homework and more than $92 \%$ of the variance in science, English and history homework is across teachers.

Of course, a natural question at this point is to ask about the source of variation of assigned homework that exists within teachers. A very straightforward explanation would be to link homework with the ability 
of students. For instance, the same teacher may assign more or less homework if he or she evaluates the classes differently. Indeed, running a simple within-teacher regression of homework on teachers' evaluation of the overall class achievement supports this hypothesis. Taking the high achievement group as the base category, the coefficient estimates for average and low achievement classes show a monotonically decreasing pattern and are highly significant. A related and similar source of variation may arise if the students in one of the classes have received bad shocks (for example, receiving a bad teacher in the past year) and are currently at risk to receive lower test scores. The important caveat to keep in mind is that we do not strongly argue that the within-teacher variation is inherently random. The variation may stem from several student, classroom and/or teacher traits. However, the empirical methodology, as well as the rich set of conditioning variables utilized in the paper facilitates the exogeneity assumption. Furthermore, as discussed below, the similarity between the fixed effect and instrumental variable coefficient estimates (though the latter is imprecisely estimated) may support the argument that the remaining (or inherently) within-teacher variation is random.

\section{Empirical methodology}

We define the educational production function as

$$
T S_{i l t}=f\left(H W_{l t}, X_{i}, Z_{l t}, \xi_{i}, \mu_{l t}\right)+\varepsilon_{i l t}
$$

where $T S$ is the test score of student $i$ in subject $l$ with teacher $t$ and $H W$ denotes the hours of weekly homework assigned in subject $l$ by teacher $t$. The vector $X$ represents observed student traits, $Z$ consists of the determinants of test score that vary at the classroom level and/or by teacher, as well as the subjectspecific fixed effects. The terms $\xi$ and $\mu$ are the student and teacher fixed effects, respectively. Finally, $\varepsilon$ is a zero mean, possibly heteroskedastic, normally distributed error term.

As noted, the design of the NELS:88 allows us to observe each student in two sampled subjects. Moreover, the surveyed teachers in the NELS:88 often teach multiple classes. Utilizing these features of 
the data, we specify the following subject-specific regression equations:

$$
\begin{aligned}
& T S_{i 1 t}=\beta H W_{1 t}+\gamma X_{i}+\theta Z_{1 t}+\xi_{i}+\mu_{1 t}+\varepsilon_{i 1 t} ; \\
& T S_{i 2 t}=\beta H W_{2 t}+\gamma X_{i}+\theta Z_{2 t}+\xi_{i}+\mu_{2 t}+\varepsilon_{i 2 t} .
\end{aligned}
$$

Equation (2) refers to student $i$ when observed in either math or science and similarly equation (3) refers to student $i$ when observed in English or history. In order for OLS estimation of (2) or (3) to provide a consistent estimate of $\beta$, the weekly assigned homework must be uncorrelated with the unobserved student and teacher traits included in the error term. However, there may be many confounding student/teacher effects that are likely to bias the estimate. Therefore, it would seem prudent to attempt to eliminate the subject invariant determinants unique to individual students and teachers. To this end, we follow the first difference procedure in Dee $(2005,2007)$ and Dee and West (2008) and subtract equation (3) from equation (2), which yields

$$
T S_{i 1 t}-T S_{i 2 t}=\beta\left(H W_{1 t}-H W_{2 t}\right)+\theta\left(Z_{1 t}-Z_{2 t}\right)+\left(\mu_{1 t}-\mu_{2 t}\right)+\left(\varepsilon_{i 1 t}-\varepsilon_{i 2 t}\right) .
$$

OLS estimation of (4) will provide a consistent estimate of $\beta$ as long as the assigned homework is uncorrelated with subject-specific traits and/or unobserved factors included in the error term. It is also important to note that describing the educational production function in the following form has the advantage of overlooking the potential confounding effects of lagged test scores. As widely known, a common practice in the educational production function literature when examining the effects of schooling related inputs on achievement is to include lagged test scores. Lagged test scores are assumed to provide an important control for ex ante achievement and their inclusion attempts to capture previous inputs in the educational production process, giving the results a "value-added" interpretation (Hanushek 1979). The value added specification is generally regarded as being better than the "contemporaneous" specification (equations 2 and 3) to obtain consistent estimates of the contemporaneous inputs. However, the value 
added specification is highly susceptible to bias even if the omitted inputs are orthogonal to the included inputs. The problem mainly arises due to the correlation between lagged test scores and (unobserved) endowed ability. If this potential endogeneity of lagged test scores is not taken into account, then the resulting bias will not only contaminate the estimate of lagged test scores but may be also transmitted to the estimates of all the contemporaneous input effects (Todd and Wolpin 2003). ${ }^{2}$

Although our first differenced equation described in equation (4) is arguably superior to a contemporaneous or value added model, it has the drawback of imposing a common effect for all subjects. It is likely that the impact of additional homework varies across subjects. In order to capture this kind of heterogeneity, we introduce interaction terms between the subject-specific assigned homework and subject fixed effects. Specifically, equations (2) and (3) take the following forms

$$
\begin{aligned}
& T S_{i 1 t}=\beta_{M} H W M_{1 t}+\beta_{S} H W S_{1 t}+\gamma X_{i}+\theta Z_{1 t}+\xi_{i}+\mu_{1 t}+\varepsilon_{i 1 t}, \\
& T S_{i 2 t}=\beta_{E} H W E_{2 t}+\beta_{H} H W H_{2 t}+\gamma X_{i}+\theta Z_{2 t}+\xi_{i}+\mu_{2 t}+\varepsilon_{i 2 t},
\end{aligned}
$$

where $H W M$ and $H W S$ in equation (5) refer to the assigned homework in math and science, respectively. $H W E$ and $H W H$ are defined similarly for English and history. Subtracting equation (6) from (5) yields

$$
\begin{aligned}
T S_{i 1 t}-T S_{i 2 t}= & \beta_{M} H W M_{1 t}+\beta_{S} H W S_{1 t}-\beta_{E} H W E_{2 t}-\beta_{H} H W H_{2 t} \\
& +\theta\left(Z_{1 t}-Z_{2 t}\right)+\left(\mu_{1 t}-\mu_{2 t}\right)+\left(\varepsilon_{i 1 t}-\varepsilon_{i 2 t}\right)
\end{aligned}
$$

Prior to continuing, a few comments are warranted regarding the potential confounding effects in the homework coefficient estimates obtained from equation (7) (or equation (4)). The estimates may yield biased results due to presence of unobserved classroom and peer traits. To (partially) overcome this

\footnotetext{
${ }^{2}$ Stinebrickner and Stinebrickner (2008) in their examination of the casual effect of studying on grade performance state that the fixed effect estimation is more problematic than OLS when first differencing is carried out in a time-use context (for example, two semesters). The authors show that fixed effect estimation performs poorly due to differential responses of fixed effect units to period-specific information. Our empirical methodology, on the other hand, utilizes a contemporaneous within-student and within-teacher framework and therefore, does not suffer from the potential contamination of periodspecific information.
} 
problem, as indicated above, we try to control for a relatively rich set of class and peer characteristics. Unobserved within-teacher heterogeneity in the assignment of homework across classes may also contaminate the coefficient estimates. Even though we condition on the teacher's assessment of the overall class achievement level in all regressions, which arguably mitigates the correlation between homework and unobserved within teacher heterogeneity, it is likely that many schools have only one advanced eighth grade class for math or science and a set of regular classes. Suppose a student in the advanced math or science class has higher ability than in English or history. The teacher fixed effect will not capture him/her giving more (or less) homework in the advanced class and under this scenario, the resulting estimates would be misleading. A similar and related source of bias pertains to nonrandom within-student assign-

ment in broad subject areas. For instance, it may be the case that students with higher propensity for achievement in similar subject areas (say, math and science) are more likely to be matched with teachers who assign more homework in those subjects. Conditioning on student fixed effects will not capture this subject-specific student trait and once again the homework coefficient estimates may suffer from selection biases. We attempt to address these concerns throughout the paper.

\section{Baseline results}

Our baseline specifications are presented in Tables 3-5. The heteroskedasticity-robust standard errors clustered at the school level are reported beneath each coefficient and all estimations include genderspecific subject fixed effects. Table 3 gives first differenced estimates of homework assuming that the return to homework is constant across subjects. Table 4 (preferred specifications) allows the returns to differ by academic subject and the fifth table allows for nonlinearities in the homework variable(s).

\subsection{Uniform returns to homework across subjects}

The first column of Table 3 shows the simple regression estimation of test scores on assigned weekly homework. In the absence of any controls, the homework coefficient yields a statistically significant value 
of $0.61(0.12)$. This implies that a one-standard deviation increase in weekly homework is associated with a gain of 0.8 points, an increase of roughly 1.6 percent relative to the sample mean test score. This model, however, is simplistic in the sense that it does not take into account many other determinants of achievement. Therefore, in the second and third columns of Table 3, we include the student characteristics and school fixed effects successively. The inclusion of both increases the estimated effect to $0.84(0.08)$.

Theoretical models that examine the relation between homework and achievement suggest that ability is strongly correlated with the effectiveness of homework. That is, higher able students benefit more from additional homework (Neilson 2005). In order to control for subject invariant ability and other unobserved student traits, the fourth column includes the student fixed effects. Adding them to the model reduces the impact of homework and the coefficient estimate is no longer different from zero. This finding indicates the existence of a positive selection bias and is consistent with theoretical models. Extending the specification to include observed teacher characteristics slightly increases the magnitude of the coefficient, but the coefficient estimate remains weakly significant. The amount of homework assigned by the teacher is likely to be a function of classroom and peer characteristics. In order to circumvent the potential correlation of assigned homework with these traits, we introduce a large set of covariates. While doing so, we take caution to not only control for basic measures such as class size or number of hours the class meets weekly, but also for measures of cognitive (teacher's evaluation of the overall class achievement level) and noncognitive (weekly number of hours spent maintaining order/discipline in class) ability, as well as crude proxies for the learning speed of the overall class (percentage of textbook covered in course, weekly number of hours spent administering tests/quizzes). Adding these variables to the model yields an insignificant homework effect of 0.07 (0.04) points.

Even though we control for the usual set of observed teacher characteristics in the educational production function, empirical studies show that these variables do not fully capture teacher quality and effectiveness (Aaronson et al. 2007; Buddin and Zamarro 2009; Kane et al. 2008; Rivkin et al. 2005; Rockoff 2004). The inability to measure these traits accurately raises concerns about the true causal effect of homework on test scores. It may be the case that less qualified/effective teachers assign more 
homework to increase overall class achievement, which would then lead to an underestimation of the return to homework. ${ }^{3}$ Moreover, the quality of the assigned homework is likely to be a function of (unobserved) teacher credentials and effectiveness. Therefore, it may be important to control for teacher fixed effects in the model. ${ }^{4}$ The eighth column of Table 3 presents the result. The estimated effect of homework increases after introducing the teacher fixed effects and once again turns out to be statistically significant at conventional levels. A one-standard deviation increase in the weekly assigned homework is associated with a gain of 0.90 points, an increase of more than 1.7 percent relative to the sample mean test score. As compared to prior specification, it appears that there is a negative association between assigned homework and unobserved teacher traits. Even though we observe a jump when we switch from column seven to eight, the lower end of the $95 \%$ confidence interval of the estimate overlaps the high end of the $95 \%$ confidence interval for the effect in the prior column that excludes the teacher fixed effects.

\subsection{Subject-specific returns to homework}

Thus far we have forced the returns to additional homework to be the same for all subjects. In Table 4, we replicate the specifications of Table 3 by allowing the effects of homework to vary across subjects as described in equation (7). In the absence of student fixed effects (columns 1-3), our results indicate that homework has a significant and positive effect for all subjects. However, once we augment the student effects to the model, the coefficient estimates drop. Specifically, assigning an additional hour of math and English homework significantly increases the corresponding test scores by $0.29(0.09)$ and $0.20(0.08)$ points, respectively. On the other hand, the effect on an additional hour of history homework on history achievement is indistinguishable from zero. Perhaps more surprisingly, additional science homework seems to significantly decrease science test scores. The $F$-test of equal effects across the four subjects is easily rejected $(p$-value $=0.00)$. Adding the observed teacher, classroom and peer characteristics (columns 5-7) to the model barely affects the coefficient estimates.

\footnotetext{
${ }^{3}$ An analogous argument that would require more effective teachers to assign more homework, which would lead to a bias in the opposite direction, can be made as well.

${ }^{4}$ Indicators for the student and teacher sharing the same gender or race are included in fixed effect regressions.
} 
In the last column of Table 4, we include the teacher fixed effects. Similar to the common homework effect model, accounting for teacher fixed effects changes the coefficient estimates and indicates the presence of negative selection biases. Specifically, the math homework coefficient yields a value of 1.29 (0.41). That is, a one standard deviation increase in the amount of weekly assigned math homework is associated with a gain of 1.77 points in math achievement, an increase of more than 3.5 percent relative to the subject-specific mean sample test score. It is also worthwhile to note that the lower end of the $95 \%$ confidence interval of the coefficient estimate overlaps the high end of the $95 \%$ confidence interval for the effect in the prior column that excludes the teacher fixed effects. Compared to column 7, controlling for unobserved teacher traits changes the sign of the science homework coefficient from negative to positive and the impact is no longer statistically significant. A similar pattern, though initially insignificant, is observed for history homework as well. With respect to English homework, even though the magnitude is similar to that of column 7 , the effect turns out to be indistinguishable from zero in the last column of Table 4.

Before continuing, some discussion is warranted with respect to our estimates from the last column of Table 4. The bias detected particularly for the math homework coefficient with teacher fixed effects suggests that assigned math homework is negatively correlated with the unobserved teacher quality; low quality teachers seem to assign more math homework. Given the level of parental involvement in the assignments, teachers may try to compensate for their limitations by giving additional homework. The negative selection bias found in this paper is consonant with several other studies that use teacher fixed effects in similar contexts. For instance, in their respective studies on the relationship between traditional measures of teacher quality (for example, teacher experience) and student achievement, Buddin and Zamarro (2009) and Rockoff (2004) find that conditioning on teacher fixed effects produces significantly larger estimates on the covariates of interest as opposed to estimation without fixed effects. Apart from this, an additional hour per week of math homework is found to be effective in improving test scores whereas additional homework in other subjects do not. ${ }^{5}$ One feasible explanation is that math homework

\footnotetext{
${ }^{5}$ It is important to note that these estimated coefficients do not imply that homework is useless in these subjects. The
} 
requires solving problems and not simple memorization. The NELS tests are learning based test. For example, the science test contains questions with a "placed emphasis on the student's understanding of underlying concepts rather than on his or her retention of isolated facts." If it is true that the tests require learning and not memorization and that homework in the other subjects have larger percentages of "memorizing exercises," then this could be an explanation of why additional homework has an insignificant effect in these subject areas. A similar argument is made by Polachek et al. (1978, pp. 222-224) regarding returns to tests from study time (memorization) versus class time (concept formation).

\subsection{Nonlinearities in the return to homework}

As a last step to our baseline specifications, we test the potential nonlinear effects of homework in Table 5 by adding quadratic homework terms. The first column presents the results under the assumption that the effect of homework is the same for all subjects. The homework squared term is negative and marginally significant, suggesting only weak evidence for diminishing returns to the amount of homework assigned. For these estimated coefficients, the return to homework becomes zero at around seven hours per week and is negative afterwards. Perhaps this can be viewed as an absolute maximum (but unlikely optimal) number of hours of homework that should be assigned to the mean student. This model suggests that anything in excess of seven hours per week would actually lead to the lowering of test scores. The remaining columns test the nonlinearity within homework by allowing the effects to vary across subjects. In columns 2-5, subject-specific quadratic homework terms enter one at a time. In the last column, we add all the quadratic homework terms at the same time. Similar to the common effect model, there is no strong evidence for diminishing returns to homework. A peculiar finding is that we find additional homework in English to be insignificant in the linear model, but marginally significant in the quadratic models.

coefficients are simply partial effects. The interpretation of the coefficients are that at current (average) levels of homework, the model predicts that an additional hour of homework per week in these three subjects will not bring a significant return to test scores. 


\subsection{Spillover effects}

In our baseline estimations, we ignore the potential spillover effects of additional homework in one subject on another. In order to examine the spillover effects, we borrow the strategy developed in Dee (2007) and estimate the effect of math (science) homework on science (math) test scores. Specifically, we replace the test score in math (science) with the test score in science (math) for each student. We employ this strategy for the model in the last column of Table 4. The existence of a large and significant effect of homework on the other subject would suggest evidence for spillover effects.

Table 6 presents the results from this exercise. The first column reports the estimates from the previous table (Column 8 of Table 4). In the remaining columns, math and science scores are replaced with science and math scores, respectively, while keeping the other subject test scores as conventionally defined. The estimated effect of math homework on science achievement is negative and statistically insignificant; the effect of science homework on math achievement is small and statistically insignificant. We also replicate the results of the last column of Table 4 after replacing the English (history) test score with the corresponding test score in history (English), while keeping the other subject test scores as conventionally defined. The estimated effects are insignificant in both cases. These results are available upon request. Taken together, these results point to the absence of spillover effects.

\subsection{Robustness checks}

\subsubsection{Subject invariant unobserved traits}

In our estimation procedure, we implicitly impose the assumption that unobserved student traits are invariant across subjects. It may be the case that students with higher (or lower) propensity for achievement in similar subject areas (say, math and science) are more likely to be assigned to teachers with more (less) homework assignments in those subjects. This subject-specific student trait may lead to an upward bias. However, the absence of spillover effects yields indirect evidence that potential nonrandom within-student assignment is not biasing our results. 


\subsubsection{Unobserved classroom/peer traits}

The second potential source of bias that we address pertains to possible confounding effects due to unobserved classroom/peer traits. Even though we try to condition on a rich set of observed characteristics, the results may still reflect a spurious relation. To shed additional light on this issue, we include peers' average GPA from grades six to eight as an additional control to the specification in the last column of Table 4. Since there is only one student observed for several classes, we restrict the sample to include four or more students in a given class $\left(12,696\right.$ student by teacher pairs). ${ }^{6}$ In the absence of the additional control, the estimated effect of math homework is $1.858(0.810)$, while the impact is $1.786(0.816)$ when we include average GPA in the model. The remaining coefficient estimates are qualitatively similar to the last column of Table 4 for both specifications. Moreover, besides acting as a robustness check, this examination shows that our identification strategy (and our estimates) is not a by-product of a small number of teachers observing multiple students from different classes.

\subsubsection{Advanced courses}

One other threat to the estimation strategy is the presence of an advanced class in math (or science) in many schools. If the student in the advanced class has higher ability in math or science than in English or history and under the assumption that the teacher assigns more homework in the advanced class, the resulting estimate for math (or science) homework can be upward biased. The teacher fixed effects will not capture this type of heterogeneity in the amount of homework assigned. To check for this possibility, we use the teachers' responses on whether they teach a gifted/talented eighth grade class. Dropping the teachers who teach a gifted/talented class from the effective sample circumvents the potential upward bias in the math coefficient because some of the classes taught by these teachers are likely to be advanced classes (21,936 student by teacher pairs). Doing so yields a value of 1.068 (0.489) for math homework coefficient and the other homework subject estimates continue to be statistically insignificant.

\footnotetext{
${ }^{6}$ The estimations are not sensitive to the choice of the number of students in a given class.
} 


\subsubsection{Instrumental variable estimation}

Even though we have examined several different potentially confounding effects, there may still be some concerns remaining with respect to our estimates. Thus, our final sensitivity check relies upon instrument variable (IV) estimation. The instrument that we use comes from the subject-specific teachers' restricted NELS:88 reports. Specifically, the subject-specific teachers are asked a series of questions about the textbook used in class, which are reported in the Appendix A. Controlling for the first six inquiries in the regressions, we utilize the last one, an indicator for whether the text book provides good suggestions for homework assignments ( $\mathrm{Yes}=1$ and $\mathrm{No}=0$ ), interacted with subject fixed effects as our instrument.

If the teachers' opinion about the textbook homework suggestions is a valid instrument, then (i) it must be a determinant of the assigned homework, but (ii) it must not be a determinant of test scores. The first stage regressions (Table B1 in the Appendix B) indicate that the subject-specific instrument is a significant determinant of the corresponding assigned homework. Moreover, the instrument fares well in terms of diagnostic tests for relevance; we reject the null of under-identification with both Anderson canonical correlations and Cragg-Donald test statistic. Thus, the reliability of the IV depends on the second condition. In the absence of multiple instruments, we can not test the second condition. However, conditional on several variables for the quality of the textbook, there is no apriori reason to believe that the teachers' subjective opinion about the textbook homework suggestions is going to affect the test scores. The IV estimates in the absence of teacher fixed effects are provided in Table B2 in the Appendix B. The math homework coefficient is imprecisely estimated but the lack of precision set aside, the effect of an additional hour of math homework is very similar to column 8 of Table 4 . This finding may provide further evidence that the within-teacher variation, conditional on observable characteristics (or inherently), is indeed random. ${ }^{7}$

Finally, if the students' unobservables were to vary across subjects and the significant math homework coefficient from the last (or other) column of Table 4 was driven by this confounding effect, we would

\footnotetext{
${ }^{7}$ We have also run an instrumental variable regression with student and teacher fixed effects. This model yields a value of 1.893 for math homework coefficient. These results are available upon request.
} 
expect similar bias in the science homework coefficient as well given that these two subjects are in similar areas.

\subsubsection{Summary}

In summary, the findings of the paper thus far provide four key insights. First, controlling for unobserved student and teacher traits in the regressions is crucial. In the absence of student (teacher) fixed effects, we observe positive (negative) selection biases. Second, the results in Table 4 suggest that a common return assumption to additional homework for all subjects is a misleading one. Allowing for subjectspecific returns prevails a statistically meaningful positive effect of additional homework solely for math achievement. Taking the Peabody Individual Achievement Test in math as our benchmark, the gain from math homework (1.77 points) corresponds to one-fourth of the raw black-white test score gap between the ages of 6 and 13 (Todd and Wolpin 2007). Another way to benchmark our estimate, which is slightly less than one-fifth of the sample standard deviation of the math test score, is to note that it is more than twice the standardized gender gap in math test scores at age 13 on the 1999 National Assessment of Educational Progress (Dee 2007). Third, there is little evidence for nonlinear effects of assigned homework once we allow for subject-specific returns. Fourth, several sensitivity checks support our findings. Given these results and in the interest of brevity, we focus on the estimates from equation (7) (Column 8 of Table 4) for the remainder of the paper. ${ }^{8}$

\section{Heterogeneous effects of homework}

Several past studies investigating the role of educational resources (for example, class size reduction) on student achievement underscore the fact that the additional benefits of these resources are not equally distributed across the population (Krueger and Whitmore 2001). To examine these kinds of differential returns in the case of homework, we allow for heterogeneous effects along three dimensions: gender, race

\footnotetext{
${ }^{8}$ We have also estimated the subject-specific returns to homework for the private school sample. The results are qualitatively similar to that of public school sample and are available upon request.
} 
and highest level of parental education. ${ }^{9}$

The first two columns of Table 7 present the results by gender. Similar to the full sample, we observe a large and statistically meaningful coefficient estimate of homework for girls in math achievement. For boys, on the other hand, the effect of additional math homework is only weakly significant. However, the magnitude of the returns to homework are very close for boys and girls.

In the next three columns we divide the sample based on race. The impact of homework across each of the four subjects is insignificant, small and actually negative on English for black students. One potential explanation for the small coefficient on math homework for black students is that, on average, they are assigned more math homework (2.52 hours per week) than any other group. However, it is the racial group that demonstrates the largest discrepancy between math homework assigned and completed (1.11 hours per week). A related explanation would state that perhaps black students are assigned too much homework and thus may have hit their time constraint (Neilson 2005) or "give-up" limit (Eren and Henderson 2008). In contrast to black students, the coefficient estimates for Hispanic students are large in magnitude. In addition, the coefficient on science homework is statistically significant. A one standard deviation increase in the assigned weekly science homework corresponds to a 4.21 point increase in science test scores, roughly 9 percent relative to their subject-specific sample mean. The results with respect to white students are similar to that of full sample.

Columns (6)-(9) report the coefficient estimates based on parental education. The results are quite interesting. For students whose parents have less than a high school diploma, the effect of homework is small and insignificant, especially in math. However, students whose parents have a high school diploma have large and significant impacts from math homework. At the same time, students whose parents have some college also have a significant impact of math homework on math test scores, but the value is less than that for parents with solely a high school diploma. The puzzling result is for students whose parents have a college degree or higher. The effect here is insignificant. The results for the first and fourth

\footnotetext{
${ }^{9}$ We also examine the effects of homework based on the family composition (intact vs. single parent family). The returns to an additional hour of homework are similar across these subgroups.
} 
parental education levels deserve an explanation. For the students whose parents have less than a high school diploma, it may be difficult for them to obtain help on their assignments from their parents. It may also be the case that these students are not completing their assignments and hence the homework has no impact. Indeed, this subgroup shows a large discrepancy between math homework assigned (2.40 hours per week) and math homework completed (1.03 hour per week). Students whose parents have a college degree or higher spent the longest amount of time completing their math homework (1.74 hours per week) and additional homework may not be helpful (for example, hit their time constraint or give-up limit). ${ }^{10}$

\section{Conclusion}

The stagnation of academic achievement in the United States has given rise to a growing literature seeking to understand the determinants of student learning. Utilizing the NELS:88 data and within-student, within-teacher comparisons, we assess the impact of a relatively unexplored input in the educational process, homework, on eighth grade student achievement.

Viewing the complete set of results, we have three striking empirical findings. First, our results indicate that controlling for unobserved student and teacher traits is crucial in order to obtain the causal effect of homework on student achievement. In the absence of student (teacher) fixed effects, we observe positive (negative) selection biases for all subject-specific homework estimates. That being said, only math homework has a consistently and statistically meaningful large effect on test scores. An additional hour of homework in science, English and history has little to no impact in our sample and moreover, there is no evidence for spillover effects across similar subjects. Second, the teachers' treatment of the homework (whether it is being recorded and/or graded) does not appear to affect the returns to math homework. Finally, when we allow for heterogeneity across the population, the coefficient estimates are similar in magnitude to that of full sample on the basis of gender. However, the impact of math homework

\footnotetext{
${ }^{10}$ We also investigate the nonlinear effects of subject-specific homework on subgroups. In none of these cases is the quadratic term statistically significant at the five-percent level.
} 
for black students relative to white students is much lower and statistically insignificant. Furthermore, there is evidence for beneficial effects of science homework for Hispanic students. With respect to parental education, the estimates reveal a meaningful effect of additional math homework for those whose parents have a high school diploma or some college.

From a policy point of view, it may be premature to conclude that additional homework is the input necessary to improve educational outcomes. On one hand, math homework helps white students and science homework helps Hispanic students. On the other hand, additional homework, although the coefficient differences, say for math homework between white and black students is not statistically different, may increase the relative performance gap for black students. A similar argument is plausible for those who come from less educated families. Moreover, homework does not appear to improve achievement in other subjects. There is also at least one caveat to keep in mind. Our data set comes from student responses from two decades ago and it is conceviable to argue that these results can not be generalizable to current educational environment. Perhaps future work can re-approach this issue in more detail. 


\section{References}

[1] Aaronson, D., L. Barrow and W. Sander (2007), "Teachers and Student Achievement in the Chicago Public High Schools," Journal of Labor Economics, 25, 95-135.

[2] Angrist, J. D. and K. Lang (2004), "Does School Integration Generate Peer Effects? Evidence from Boston's Metco Program," American Economic Review, 94, 1613-1634.

[3] Aksoy, T. and C. R. Link (2000), "A Panel Analysis of Student math Achievement in the US in the 1990s: Does Increasing the Amount of Time in Learning Activities Affect Math Achievement?" Economics of Education Review, 19, 261-277.

[4] Betts, J. R. (1997), "The Role of Homework in Improving School Quality," Unpublished Manuscript, Department of Economics, University of California, San Diego.

[5] Bok, E. (1900), "A National Crime at the Feet of American Parents," Ladies Home Journal, 17, 16.

[6] Buddin, R. and G. Zamarro (2009), "Teacher Qualifications and Student Achievement in Urban Elementary Schools," Journal of Urban Economics, 66, 103-115.

[7] California Civil Code. 34th session, 1901, sec. 1665.

[8] Cooper, H. (1994), The Battle over Homework: An Administrator's Guide to Setting Sound and Effective Policies, Corwin: Thousand Oaks.

[9] Dee, T. S. (2005), “A Teacher Like Me: Does Race, Ethnicity, or Gender Matter?" American Economic Review, 95, 158-165.

[10] Dee, T. S. (2007), "Teachers and the Gender Gaps in Student Achievement," Journal of Human Resources, 42, 528-544.

[11] Dee, T. S. and M. West (2008), "The Non-Cognitive Returns to Class Size," NBER Working Paper, No. 13994. 
[12] Eren, O. and D. J. Henderson (2007), "The Impact of Homework on Student Achievement," Econometrics Journal, 11, 326-348.

[13] Figlio, D. N. and M. E. Lucas (2003), "Do High Grading Standards Affect Student Performance?" Journal of Public Economics, 88, 1815-1834.

[14] Fuchs, T. and L. Wößmann (2007), "What Accounts for International Differences in Student Performance? A Re-Examination Using PISA Data," Empirical Economics, 32, 433-464.

[15] Gill, B. and S. Scholssman (1996), "A Sin against Childhood': Progressive Education and the Crusande to Abolish Homework, 1897-1941," American Journal of Education, 105, 27-66.

[16] Hanushek, E. A. (1979), "Conceptual and Empirical Issues in the Estimation of Educational Production Functions," Journal of Human Resources, 14, 351-388.

[17] Hanushek, E. A. (2003), "The Failure of Input Based Schooling Policies," Economic Journal, 113, 64-98.

[18] Hoxby, C. M. (1999), "The Productivity of Schools and Other Local Public Goods Producers," Journal of Public Economics, 74, 1-30.

[19] Kane, T. J., J. E. Rockoff and D. O. Staiger (2008), "What Does Certification Tell Us about Teacher Effectiveness? Evidence from New York City," Economics of Education Review, 27, 615-631.

[20] Krueger, A. B. and D. M. Whitmore (2001), "The Effect of Attending a Small Class in the Early Grades on College-Test Taking and Middle School Test Results: Evidence from Project Star,” Economic Journal, 111, F1-F28.

[21] Neilson, W. (2005), "Homework and Performance for Time-Constrained Students," Economics Bulletin, 9, 1-6.

[22] Polachek, S. W., T. J. Kniesner and H. J. Harwood (1978), "Educational Production Functions," Journal of Educational Statistics, 3, 209-231. 
[23] Rice, J. M. (1897), "The Futility of the Spelling Grind," Forum, 23, 163-172.

[24] Rivkin, S. G., E. A. Hanushek and J. F. Kain (2005), "Teachers, Schools and Academic Achievement," Econometrica, 73, 417-458.

[25] Rockoff, J. E. (2004), "The Impact of Individual Teachers on Student Achievement: Evidence from Panel Data," American Economic Review, 94, 247-252.

[26] Stinebrickner, R. and T. R. Stinebrickner (2008), "The Casual Effect of Studying on Academic Perfomance," The B.E. Journal of Economic Analysis $\& 3$ Policy, 8, Article 14.

[27] Todd, P. E. and K. I. Wolpin (2003), "On the Specification and Estimation of the Production Function for Cognitive Achievement," Economic Journal, 113, 3-33.

[28] Todd, P. E. and K. I. Wolpin (2007), "The Production of Cognitive Achievement in Children: Home, School and Racial Test Score Gaps," Journal of Human Capital, 1, 91-136.

[29] Walsh, P. (2010), "Is Parental Involvement Lower at Larger Schools?" Economics of Education Review, 29, 959-970.

[30] What Works (1986), U.S. Department of Education: Washington. 


\begin{tabular}{|c|c|c|c|c|}
\hline & \multicolumn{2}{|c|}{ Public School Sample } & \multicolumn{2}{|c|}{ Regression Sample } \\
\hline & Mean & SD & Mean & SD \\
\hline Test Score & 49.542 & 9.944 & 49.762 & 9.914 \\
\hline Math Test Score & 49.577 & 9.939 & 49.747 & 9.916 \\
\hline Science Test Score & 49.735 & 10.018 & 50.007 & 9.980 \\
\hline English Test Score & 49.295 & 9.805 & 49.356 & 9.780 \\
\hline History Test Score & 49.576 & 10.019 & 49.955 & 9.708 \\
\hline Assigned Weekly Hours of Homework & 2.158 & 1.312 & 2.138 & 1.301 \\
\hline Female & 0.503 & 0.499 & 0.504 & 0.499 \\
\hline \multicolumn{5}{|l|}{ Race } \\
\hline Black & 0.134 & 0.341 & 0.123 & 0.329 \\
\hline Hispanic & 0.137 & 0.344 & 0.117 & 0.322 \\
\hline Other & 0.059 & 0.235 & 0.098 & 0.297 \\
\hline White & 0.668 & 0.470 & 0.660 & 0.473 \\
\hline$\%$ of Teachers Holding a Graduate Degree & 0.462 & 0.498 & 0.460 & 0.498 \\
\hline \multicolumn{5}{|l|}{ Teacher's Race } \\
\hline Black & 0.091 & 0.288 & 0.086 & 0.281 \\
\hline Hispanic & 0.024 & 0.155 & 0.021 & 0.143 \\
\hline Other & 0.009 & 0.097 & 0.009 & 0.097 \\
\hline White & 0.873 & 0.332 & 0.882 & 0.321 \\
\hline \multicolumn{5}{|c|}{ Teacher's Evaluation of the Overall Class Achievement } \\
\hline High Level & 0.245 & 0.430 & 0.246 & 0.431 \\
\hline Average Level & 0.382 & 0.486 & 0.386 & 0.487 \\
\hline Low Level & 0.188 & 0.390 & 0.183 & 0.386 \\
\hline Wid ely Differing & 0.183 & 0.387 & 0.183 & 0.386 \\
\hline Class Size & 24.506 & 5.867 & 24.380 & 5.763 \\
\hline Number of Observations & 16,901 & & 12,897 & \\
\hline
\end{tabular}

NOTES: The variables are only a subset of those utilized in the analysis. The remainder are excluded in the interest of brevity. The full set of sample statistics are available upon request. 
Table 2: Means and Standard Deviations of Weekly Assigned Homework by Academic Subject

\begin{tabular}{l|cccc}
\hline \hline & Mean & SD & $\begin{array}{c}\text { Within-Teacher } \\
\text { SD }\end{array}$ & $\begin{array}{c}\text { Fraction of Variance } \\
\text { Across Teachers }\end{array}$ \\
\hline Math Homework & 2.415 & 1.375 & 0.489 & 0.873 \\
Science Homework & 1.795 & 1.106 & 0.248 & 0.949 \\
English Homework & 2.214 & 1.347 & 0.344 & 0.934 \\
History Homework & 2.113 & 1.247 & 0.342 & 0.924 \\
\hline \hline
\end{tabular}

NOTES: The fraction of variance across teachers is computed as $\left.\left\{(\mathrm{SD})^{2} \text {-(Within-Teacher } \mathrm{SD}\right)^{2}\right\} /(\mathrm{SD})^{2}$. 


\begin{tabular}{|c|c|c|c|c|c|c|c|c|}
\hline & \multicolumn{8}{|c|}{ Specification } \\
\hline & (1) & (2) & (3) & (4) & (5) & (6) & (7) & (8) \\
\hline Homework & $\begin{array}{c}0.618 * * * \\
(0.122)\end{array}$ & $\begin{array}{c}0.518 * * * \\
(0.081)\end{array}$ & $\begin{array}{c}0.843^{\text {*** }} \\
(0.081)\end{array}$ & $\begin{array}{c}0.077 \\
(0.048)\end{array}$ & $\begin{array}{c}0.092 * \\
(0.048)\end{array}$ & $\begin{array}{c}0.096 * * \\
(0.048)\end{array}$ & $\begin{array}{c}0.069 \\
(0.048)\end{array}$ & $\begin{array}{l}0.688^{* *} \\
(0.275)\end{array}$ \\
\hline \multicolumn{9}{|l|}{ Other Controls: } \\
\hline Student Characteristics & No & Yes & Yes & No & No & No & No & No \\
\hline School Fixed Effects & No & No & Yes & No & No & No & No & No \\
\hline Student Fixed Effects & No & No & No & Yes & Yes & Yes & Yes & Yes \\
\hline Teacher Characteristics & No & No & No & No & Yes & Yes & Yes & No \\
\hline Classroom Characteristics & No & No & No & No & No & Yes & Yes & Yes \\
\hline Peer Characteristics & No & No & No & No & No & No & Yes & Yes \\
\hline Teacher Fixed Effects & No & No & No & No & No & No & No & Yes \\
\hline
\end{tabular}

NOTES: Standard errors, adjusted for school-level clustering, are presented in parentheses. All models include gender-specific subject fixed effects. See text for definition of the variables.

$*$ significant at $10 \%, * *$ significant at $5 \%, * * *$ significant at $1 \%$. 


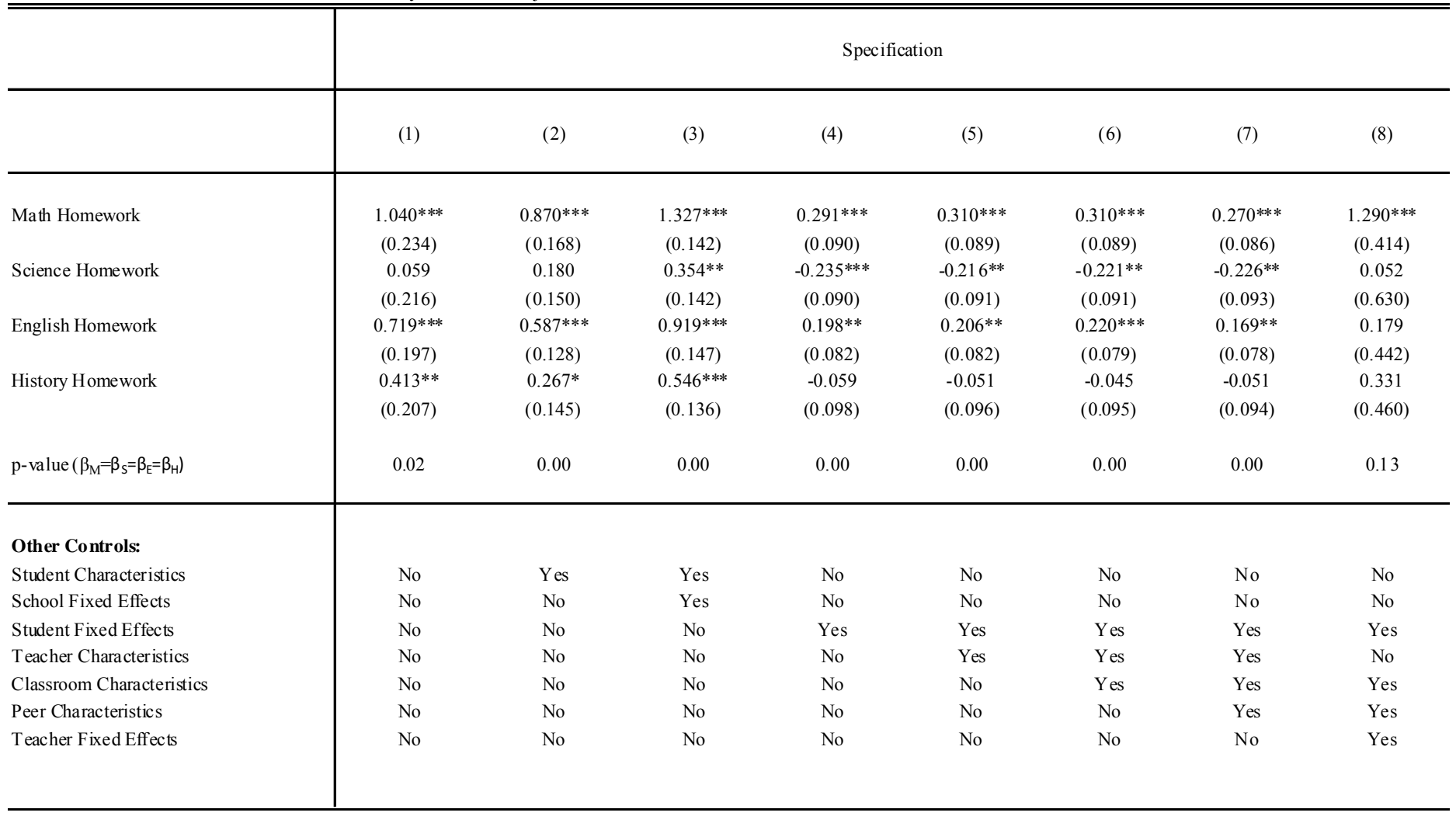

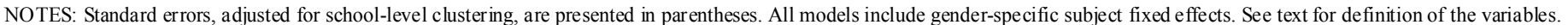

$*$ significant at $10 \%, * *$ signific ant at $5 \%, * * *$ signific ant at $1 \%$. 


\begin{tabular}{|c|c|c|c|c|c|c|}
\hline & (1) & (2) & (3) & (4) & (5) & (6) \\
\hline Homework & $\begin{array}{l}1.512 * * \\
(0.612)\end{array}$ & $\ldots$ & $\ldots \ldots$ & $\ldots \ldots$ & $\ldots$ & $\ldots \ldots$ \\
\hline Homework Squared & $\begin{array}{c}-0.103 * \\
(0.062)\end{array}$ & … & $\ldots \ldots$ & … & .... & $\cdots \cdots$ \\
\hline Math Homework & $\ldots \ldots$ & $\begin{array}{c}2.332 * * \\
(0.951)\end{array}$ & $\begin{array}{c}1.287 * * * \\
(0.414)\end{array}$ & $\begin{array}{c}1.317 * * * \\
(0.416)\end{array}$ & $\begin{array}{c}1.292 * * * \\
(0.416)\end{array}$ & $\begin{array}{l}2.404 * * \\
(0.952)\end{array}$ \\
\hline Math Homework Squared & & $\begin{array}{l}-0.137 \\
(0.101)\end{array}$ & $\ldots \ldots$ & $\ldots \ldots$ & $\ldots \ldots$ & $\begin{array}{c}-0.143 \\
(0.101)\end{array}$ \\
\hline Science Homework & $\ldots$. & $\begin{array}{c}0.055 \\
(0.632)\end{array}$ & $\begin{array}{c}-0.452 \\
(1.239)\end{array}$ & $\begin{array}{c}0.075 \\
(0.640)\end{array}$ & $\begin{array}{c}0.058 \\
(0.630)\end{array}$ & $\begin{array}{c}-0.316 \\
(1.248)\end{array}$ \\
\hline Science Homework Squared & & $\ldots$. & $\begin{array}{c}0.083 \\
(0.166)\end{array}$ & $\ldots \ldots$ & $\ldots$. & $\begin{array}{c}0.066 \\
(0.169)\end{array}$ \\
\hline English Homework & $\ldots \ldots$ & $\begin{array}{c}0.237 \\
(0.448)\end{array}$ & $\begin{array}{c}0.167 \\
(0.443)\end{array}$ & $\begin{array}{c}1.459 \\
(0.904)\end{array}$ & $\begin{array}{c}0.180 \\
(0.442)\end{array}$ & $\begin{array}{c}1.546^{*} \\
(0.921)\end{array}$ \\
\hline English Homework Squared & & $\ldots$. & $\ldots$. & $\begin{array}{c}-0.165^{*} \\
(0.091)\end{array}$ & $\ldots$. & $\begin{array}{c}-0.170 * \\
(0.093)\end{array}$ \\
\hline History Homework & ..... & $\begin{array}{c}0.321 \\
(0.453)\end{array}$ & $\begin{array}{c}0.324 \\
(0.458)\end{array}$ & $\begin{array}{c}0.340 \\
(0.463)\end{array}$ & $\begin{array}{c}0.471 \\
(1.261)\end{array}$ & $\begin{array}{c}0.539 \\
(1.259)\end{array}$ \\
\hline History Homework Squared & & $\ldots$. & $\ldots \ldots$ & $\ldots$. & $\begin{array}{l}-0.016 \\
(0.117)\end{array}$ & $\begin{array}{c}-0.025 \\
(0.115)\end{array}$ \\
\hline Other Controls: & & & & & & \\
\hline Student Characteristics & No & No & No & No & No & No \\
\hline School Fixed Effects & No & No & No & No & No & No \\
\hline Student Fixed Effects & Yes & Yes & Yes & Yes & Yes & Yes \\
\hline Teacher Characteristics & No & No & No & No & No & No \\
\hline Classroom Characteristics & Yes & Yes & Yes & Yes & Yes & Yes \\
\hline Peer Characteristics & Yes & Yes & Yes & Yes & Yes & Yes \\
\hline Teacher Fixed Effects & Yes & Yes & Yes & Yes & Yes & Yes \\
\hline
\end{tabular}

NOTES: Standard errors, adjusted for school-level clustering, are presented in parentheses. All models include gender-specific subject fixed effects. See text for definition of the variables.

$*$ significant at $10 \%, * *$ significant at $5 \%, * * *$ significant at $1 \%$. 


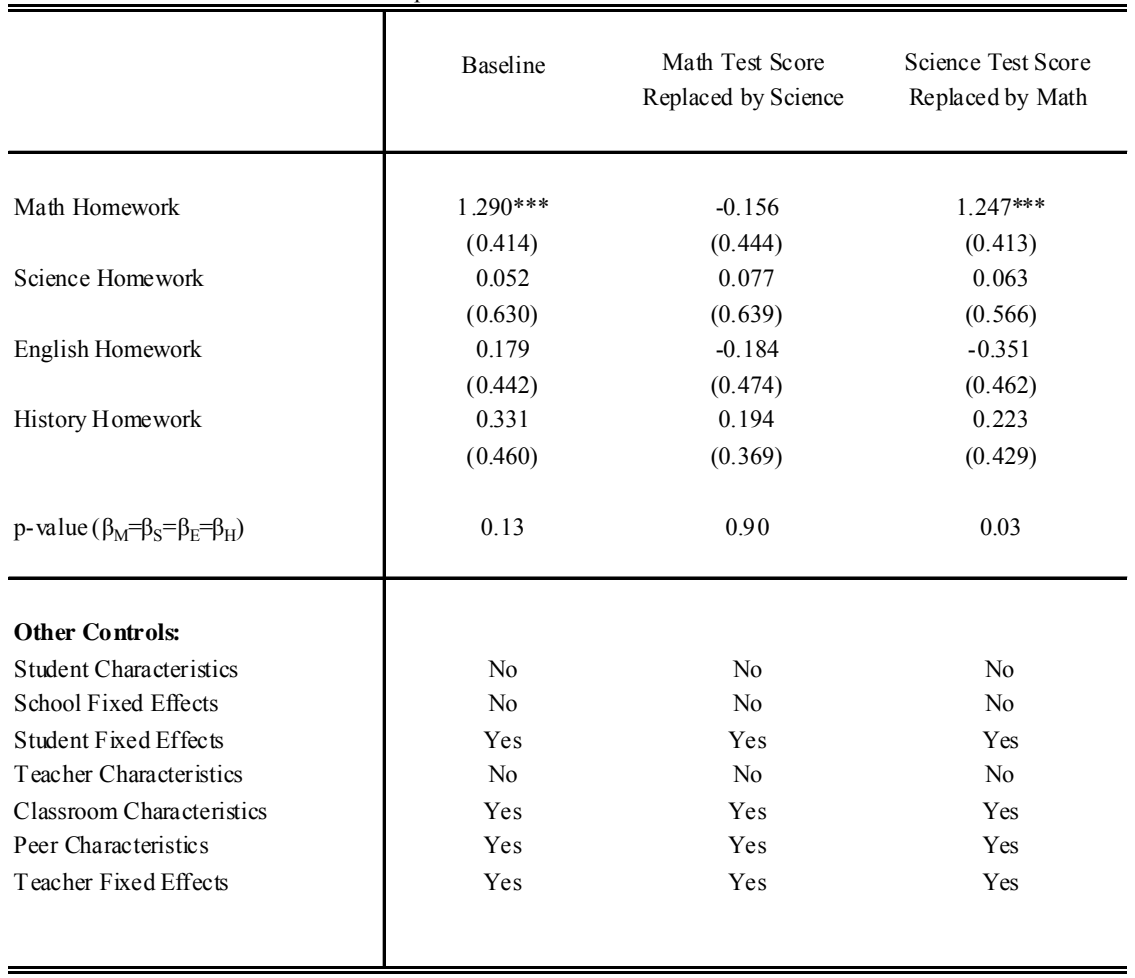

NOTES: Standard errors, adjusted for school-level clustering, are presented in parentheses. All models include gender-specific subject fixed effects. See text for definition of the variables.

$*$ significant at $10 \%,{ }^{* *}$ signific ant at $5 \%,{ }^{* * *}$ significant at $1 \%$. 
Table 7: First Differenced Estimates of Homework by Academic Subject and Student Traits

\begin{tabular}{|c|c|c|c|c|c|c|c|c|c|}
\hline & (1) & (2) & (3) & (4) & (5) & (6) & (7) & (8) & (9) \\
\hline & \multicolumn{2}{|c|}{ Gender } & \multicolumn{3}{|c|}{ Race } & \multicolumn{4}{|c|}{ Highest Level of Parental Education } \\
\hline & Boys & Girls & Blacks & Hispanics & Whites & Less Than HS & HS & Some College & College or More \\
\hline \multirow[t]{2}{*}{ Math Homework } & $1.205^{*}$ & $1.367^{* *}$ & 0.573 & 1.782 & $1.317 * * *$ & 0.147 & $2.539 * *$ & $1.497 * *$ & 1.056 \\
\hline & $(0.673)$ & $(0.560)$ & $(1.736)$ & $(3.471)$ & $(0.483)$ & $(1.873)$ & $(1.302)$ & $(0.783)$ & $(1.066)$ \\
\hline \multirow[t]{2}{*}{ Science Homework } & -0.028 & -0.096 & 0.401 & $3.810^{* *}$ & -0.307 & 0.738 & -1.088 & -0.052 & 0.136 \\
\hline & $(1.023)$ & $(1.464)$ & $(3.148)$ & $(1.938)$ & $(0.733)$ & $(5.079)$ & $(3.670)$ & $(1.791)$ & $(2.744)$ \\
\hline \multirow[t]{2}{*}{ English Homework } & 0.226 & 0.382 & -0.873 & 1.627 & 0.442 & 0.275 & -0.529 & 0.488 & -0.010 \\
\hline & $(0.753)$ & $(0.831)$ & $(0.679)$ & $(3.821)$ & $(0.630)$ & $(3.079)$ & $(1.803)$ & $(0.771)$ & $(1.532)$ \\
\hline \multirow[t]{2}{*}{ History Homework } & 0.513 & 0.201 & 0.423 & 3.756 & -0.030 & -1.910 & 2.189 & -0.135 & 0.091 \\
\hline & $(0.728)$ & $(0.781)$ & $(1.718)$ & $(4.042)$ & $(0.548)$ & $(2.801)$ & $(2.381)$ & $(0.522)$ & $(2.428)$ \\
\hline$p$-value $\left(\beta_{\mathrm{M}}=\beta_{\mathrm{S}}=\beta_{\mathrm{E}}=\beta_{\mathrm{H}}\right)$ & 0.63 & 0.51 & 0.78 & 0.91 & 0.14 & 0.89 & 0.44 & 0.36 & 0.93 \\
\hline Sample Size & 6,395 & 6,502 & 1,594 & 1,521 & 8,514 & 1,475 & 2,760 & 5,537 & 3,038 \\
\hline \multicolumn{10}{|l|}{ Other Controls: } \\
\hline Student Characteristics & No & No & No & No & No & No & No & No & No \\
\hline School Fixed Effects & No & No & No & No & No & No & No & No & No \\
\hline Student Fixed Effects & Yes & Yes & Yes & Yes & Yes & Yes & Yes & Yes & Yes \\
\hline Teacher Characteristics & No & No & No & No & No & No & No & No & No \\
\hline Classroom Characteristics & Yes & Yes & Yes & Yes & Yes & Yes & Yes & Yes & Yes \\
\hline Peer Characteristics & Yes & Yes & Yes & Yes & Yes & Yes & Yes & Yes & Yes \\
\hline Teacher Fixed Effects & Yes & Yes & Yes & Yes & Yes & Yes & Yes & Yes & Yes \\
\hline
\end{tabular}

NOTES: Standard errors, adjusted for school-level clustering, are presented in parentheses. Columns 3-9 include gender-specific subject fixed effects. See text for definition of the variables. * significant at $10 \%$, ** significant at $5 \%$, *** significant at $1 \%$. 


\section{Appendix A: Textbook Survey Questions from the Restricted NELS:88 Teach-}

ers' Reports

- How often do you make use of a textbook in your class? (Frequently, Occasionally, Rarely)

- This textbook is at a reading level which is too difficult for my students.

- This textbook helps develop problem solving skills.

- This textbook explains concepts clearly.

- This textbook does a good job covering the subject area.

- This textbook is considered interesting by most students in the class.

- This textbook provides good suggestions for homework assignment. 


\section{Appendix B: Instrumental Variable Estimation}

Table B1: Weak Instrument Tests

\begin{tabular}{|c|c|}
\hline & Dependent Variable: Subject-Specific Assigned Homework \\
\hline & $\begin{array}{c}\text { Coefficient } \\
\text { (Standard Error) }\end{array}$ \\
\hline Math Textbook Homework Suggestions & $0.187^{* * *}$ \\
\hline Science Textbook Homework Suggestions & $\begin{array}{c}0.340^{* * *} \\
(0.027)\end{array}$ \\
\hline English Textbook Homework Suggestions & $\begin{array}{c}0.255^{* * *} \\
(0.035)\end{array}$ \\
\hline History Textbook Homework Suggestions & $\begin{array}{c}0.191 * * * \\
(0.032)\end{array}$ \\
\hline Anderson Canonical Correlations (p-value) & 0.00 \\
\hline Cragg-Donald Test Statistics (p-value) & 0.00 \\
\hline Other Controls: & \\
\hline Student Characteristics & No \\
\hline School Fixed Effects & No \\
\hline Student Fixed Effects & Yes \\
\hline Teacher Characteristics & Yes \\
\hline Classroom Characteristics & Yes \\
\hline Peer Characteristics & Yes \\
\hline Teacher Fixed Effects & No \\
\hline
\end{tabular}




\begin{tabular}{|c|c|}
\hline & (1) \\
\hline Math Homework & $\begin{array}{c}1.523 \\
(1.700)\end{array}$ \\
\hline Science Homework & $\begin{array}{l}-0.836 \\
(0.581)\end{array}$ \\
\hline English Homework & $\begin{array}{c}0.107 \\
(0.962)\end{array}$ \\
\hline History Homework & $\begin{array}{c}0.193 \\
(1.151)\end{array}$ \\
\hline Sample Size & 12,320 \\
\hline Other Controls: & \\
\hline Student Characteristics & No \\
\hline School Fixed Effects & No \\
\hline Student Fixed Effects & Yes \\
\hline Teacher Characteristics & Yes \\
\hline Classroom Characteristics & Yes \\
\hline Peer Characteristics & Yes \\
\hline Teacher Fixed Effects & No \\
\hline
\end{tabular}

NOTES: The model includes the textbook quality variables (the first six questions) from Appendix A, as well as gender-specific subject fixed effects. The final question from Appendix A is used as instrument. See text for definition of the variables. 